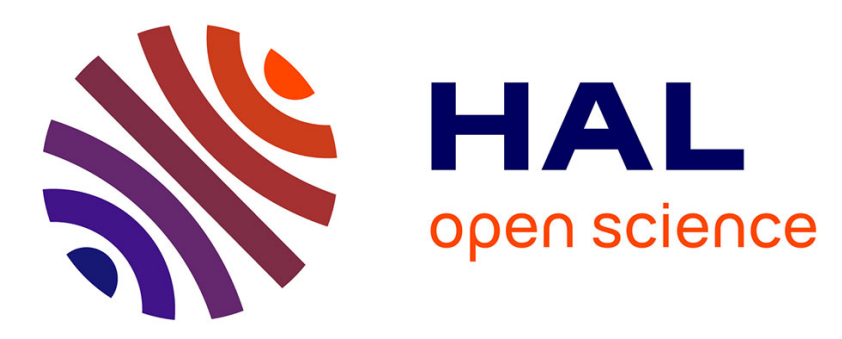

\title{
Analytical and experimental investigations of gas turbine model combustor acoustics operated at atmospheric pressure
}

Franck Richecoeur, Thierry Schuller, Ammar Lamraoui, Sébastien Ducruix

\section{- To cite this version:}

Franck Richecoeur, Thierry Schuller, Ammar Lamraoui, Sébastien Ducruix. Analytical and experimental investigations of gas turbine model combustor acoustics operated at atmospheric pressure. Comptes Rendus Mécanique, 2013, 341, pp.141-151. 10.1016/j.crme.2012.11.008 . hal-00780825

\section{HAL Id: hal-00780825 \\ https://hal.science/hal-00780825}

Submitted on 24 Jan 2013

HAL is a multi-disciplinary open access archive for the deposit and dissemination of scientific research documents, whether they are published or not. The documents may come from teaching and research institutions in France or abroad, or from public or private research centers.
L'archive ouverte pluridisciplinaire HAL, est destinée au dépôt et à la diffusion de documents scientifiques de niveau recherche, publiés ou non, émanant des établissements d'enseignement et de recherche français ou étrangers, des laboratoires publics ou privés. 


\title{
Analytical and experimental investigations of gas turbine model combustor acoustics operated at atmospheric pressure
}

\author{
F. Richecoeur, T. Schuller, A. Lamraoui, S. Ducruix \\ CNRS, UPR 288 - Laboratoire EM2C, 92290 Châtenay-Malabry, FRANCE \\ École Centrale Paris, 92290 Châtenay-Malabry, FRANCE
}

\begin{abstract}
When coupled to acoustics, unsteady heat release oscillations may cause recurrent problems in many combustion chambers, potentially leading to dramatic damages to the structure. Accumulation of acoustic energy around the eigenmodes of the combustor results from the resonant coupling between pressure disturbances in the flame region with synchronized heat release rate perturbations. Predicting these frequencies and the corresponding sound pressure field is a key issue to design passive or active control systems to prevent the growth of these instabilities. In this study, an acoustically controlled combustion test bench CESAM is used to stabilize a partially premixed swirling propane-air flame. In the premixing tube, reactants are injected tangentially to generate the swirling flow, the flame being stabilized in the combustion chamber by a sudden expansion of the cross section. The premixer backplane is equipped with an Impedance Control System (ICS) allowing to adjust the acoustic reflection coefficient at this location. Acoustics of the coupled-cavitiy system formed by the premixer and the combustion chamber is investigated analytically by taking into account the measured acoustic impedances at the premixer backplane and in the feeding lines. The chamber length is also modified to examine effects of the geometry on these predictions. It is shown that the premixer and combustion chamber can be considered as acoustically decoupled for small values of the acoustic coupling index, defined in the article, offering flexible solutions to control the pressure distribution within the combustor, except when these frequencies match. When the frequencies are close to each others, only the analysis of the damping of the different cavities enables to indicate wether the system is coupled or not. Modifying either the acoustic coupling index or the damping values featuring the same frequency appears then as alternative solutions to decouple cavities.
\end{abstract}

Résumé Les instabilités de combustion posent des problèmes récurrents dans les foyers de combustion et peuvent causer des dommages importants et irréversibles aux structures. L'accumulation d'énergie acoustique au voisinage des modes propres du système résulte d'un couplage résonant entre les perturbations de pression et du taux de dégagement de chaleur dans la zone de réaction. La prévision de ces fréquences et du champ acoustique associé est importante pour optimiser la conception des systèmes de contrôle actif ou passif empêchant l'amplification de ces instabilités. Dans cette étude, le banc de combustion CESAM est utilisé pour stabiliser des flammes propane-air swirlées partiellement prémélangées. Dans le tube de prémélange, les réactifs sont injectés tangentiellement pour mettre en rotation l'écoulement, la flamme étant stabilisée dans la chambre de combustion par une expansion brusque de la section. Le fond du tube de mélange est équipé d'un système de contrôle d'impédance (ICS) permettant d'ajuster le coefficient de réflexion acoustique. L'acoustique de ce système de cavités couplées est étudiée analytiquement en prenant en compte l'impédance acoustique mesurée au fond du tube de prémélange et dans les lignes d'alimentation. La longueur de la chambre est aussi modifiée pour examiner les effets de la
Article
submitted
to
3rd
INCA
Colloquim 
géométrie sur ces prévisions. On montre que le tube de prémélange et la chambre peuvent être considérés comme acoustiquement découplées pour des valeurs faibles de l'indice de couplage défini ici excepté dans la région où les fréquences sont voisines. Dans ce cas, seule l'analyse de l'amortissement de chacun des modes permet de déterminer si les deux cavités sont couplées ou non. Il est par conséquent possible de découpler acoustiquement deux cavités en jouant sur l'indice de couplage ou bien en modifiant l'amortissement de l'une des cavités lorsque leur fréquences propres sont proches. 


\section{Introduction}

Analysis of the acoustic modes of a combustor is often a preliminary and necessary step before envisaging the prediction of acoustically coupled combustion instabilities and resulting combustion noise production $[3,4]$. It is well known that the frequencies of unstable combustion oscillation modes lie close to the acoustic modes of the combustion system $[18,31,6,12]$. The determination of the acoustic modes and the corresponding sound pressure distribution are also important issues to identify the possible locations of passive and active control devices to hinder these self-sustained oscillations [13,20].

This problem does not require to solve the full compressible unsteady Navier-Stokes equations, and simpler alternatives have been developed. A current approach adapted to complex geometries is to solve the Helmholtz equation [30,21] or the linearized Euler equations [15,25] when mean flow effects cannot be neglected. This type of simulations now include local modifications of the mean sound celerity due to changes in the gases composition and temperature throughout the combustor $[24,2]$ and complex impedances at the boundaries [14]. It is also possible to account for acoustic dissipation [23] or effects of dampers $[1,16]$.

At low frequencies, only longitudinal waves propagate and geometrical details do not need to be considered in the models. Networks of compact acoustic elements constitute then an interesting low order solution to model the combustor acoustics $[7,19]$. In this case, it is also useful to develop an analytical representation of the system studied to gain insight on the physics and easily determine the main governing parameters controlling the acoustics of these coupled cavities. This problem has for example been envisaged by Tran [27] and later by Lamraoui [9] to model the acoustic response of a swirled injector in a premixing tube connected to a combustion chamber. The originality of this setup is that it is equipped with a perforated plate and a back cavity at the premixer inlet location that are used to control its impedance. It was found by Tran et al. $[28,29]$ that this constitutes an efficient way to damp lowfrequency unstable modes reaching a sound pressure level up to $140 \mathrm{~dB}$ in a gas turbine model combustor operated at thermal powers ranging from 30 to $65 \mathrm{~kW}$. By modifying the premixer inlet impedance, it was possible to reduce the sound level by about one order of magnitude in all cases explored for the same flow operating conditions. This is also demonstrated numerically by Gullaud and Nicoud [8]. In the present study, a theoretical analysis is conducted to model the acoustic response of this test rig and examine effects of changes of the premixer inlet impedance and modifications of the chamber length on the sound pressure distribution in the combustor. Predictions are then compared to measurements obtained under reactive conditions for two chamber lengths and different inlet reflection coefficients. On a control point of view, the objective is to show that it is possible to damp unstable modes coupled to the premixer or combustion chamber cavities by only modifying the premixed inlet boundary condition.

In the first section, the experimental setup and diagnostics are presented. Two operating points are chosen for the present study with two different chamber lengths but with similar thermal power outputs. Acoustic measurements are presented in details in the second section. In particular, Power Spectral Densities (PSD) and pressure distributions within the combustor are presented to highlight the effect of the chamber length on the acoustics. In the third section, a two-cavity model is used to estimate the acoustic response of the combustor. In this description, each cavity represents one element of the combustor, the premixer and chamber, which are interconnected. The eigenmodes of this coupled system are compared to the modes of each cavity calculated separately. This analysis highlights the evolution of pressure distribution for the different geometries and operating conditions investigated. An improved version featuring five cavities taking into account effects of the feeding lines is proposed in the final section to account for acoustic dissipation.

Email address: franck.richecoeur@ecp.fr (F. Richecoeur). 


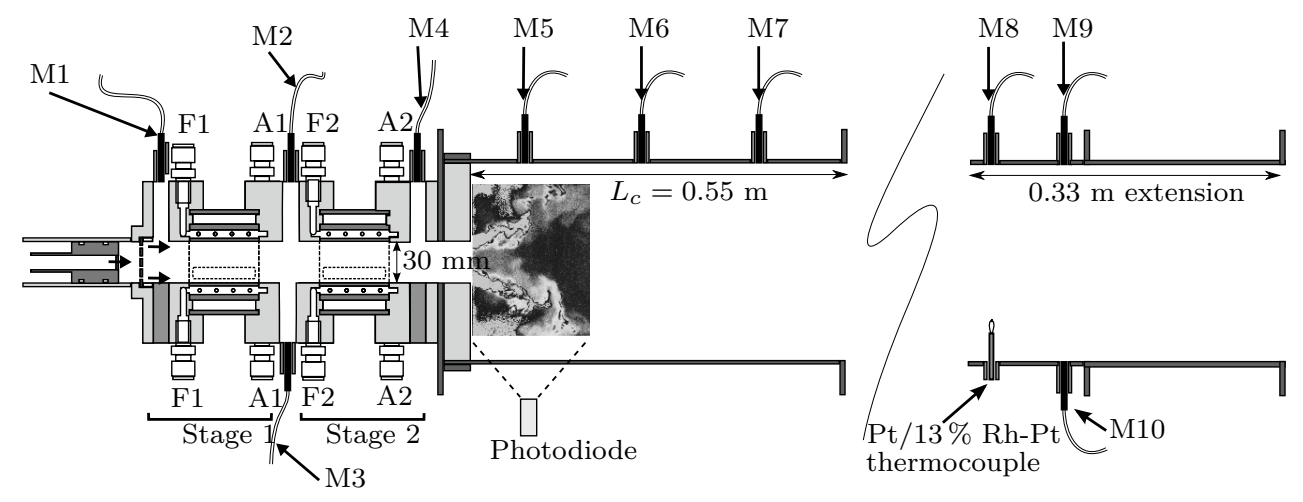

Figure 1. CESAM test bench fed with propane and air through two identical stages: each stage is fed with two inlets for propane (F1 for stage 1 and F2 for stage 2) and two inlets for air (A1 for stage 1 and A2 for stage 2). The locations of microphones M1 to M10, the photodiode and the thermocouple are also indicated.

\section{Experimental setup}

The experimental facility sketched in Fig. 1 is composed of a partially premixing cylindrical tube connected to a rectangular combustion chamber with a square $10 \times 10 \mathrm{~cm}^{2}$ cross-section. The premixer is composed of two identical stages in which tangential injections of air and propane put the flow in rotation with a theoretical swirl number of 0.7 in the $30-\mathrm{mm}$ diameter premixer. Each stage is fed with two air (A1-A2) and two fuel (F1-F2) supplying pipes that are connected to mass flow controllers through a pipe network. This burner operates in lean conditions for equivalence ratios $\Phi$ ranging between 0.7 and 0.95 . It is connected to the combustion chamber through a ceramic junction. The chamber is composed of two quartz windows on each lateral side and refractory concrete walls on top and bottom. The premixing tube manifold has a length $L_{p}=23.5 \mathrm{~cm}$. It is equipped with acoustic waveguides connected to microphones M1, M2, M3 and M4 to characterize the pressure distribution in this element and the premixer inlet reflection coefficient. The top of the combustion chamber is also equipped with three regularly spaced waveguides connected to microphones M5, M6 and M7 to characterize the pressure distribution in this region. An additional element with the same type of arrangement connected to microphones M8, M9 and M10 can be used to analyze the sound pressure distribution with a longer chamber. For the same total mass flow injected $\dot{m}=14.75$ g.s ${ }^{-1}$, this configuration features self-sustained combustion oscillations depending on the equivalence ratio $\Phi$ and the fuel staging ratio $\alpha$, defined as the ratio of the fuel mass flow in the stage furthest from the chamber (stage 1) to the total fuel mass flow injected. This staging parameter can be varied between 10 and $55 \%$, beyond this latter value the swirling flame penetrates the premixing tube and heats dangerously the premixer (flashback risks). To prevent this risk inside the premixer, air is injected axially from the rear side of the burner with a reduced mass flow corresponding to a small fraction of the total tangential mass flow injected in the system $(\approx 2.5 \%)$. This air flow is also used as the bias flow in the Impedance Control System defined below. The flame takes an inverted conical shape with a strong internal recirculation zone, typical of swirl-stabilized configurations. The flame is compact, about $15 \mathrm{~cm}$ long, and is shown at scale with the burner geometry in Fig. 1.

One specificity of this gas turbine model combustor is that the burner inlet is equipped with an impedance control system (ICS) composed of a perforated plate backed by an adjustable length cavity with a mean bias flow. This system can be used to easily tune the modulus of the reflection coefficient at the premixer inlet to the desired value even for high amplitude pressure fluctuations. This control system was adapted to the combustion facility and efficient damping of combustion instabilities was proved [28]. 
Table 1

Operating points used in the present investigation. The equivalence and staging ratio were slightly modified for the two chamber lengths, the global thermal power being roughly kept constant.

\begin{tabular}{l|c|c|c|c}
\hline & $\begin{array}{c}\text { Chamber } \\
\text { length }[\mathrm{cm}]\end{array}$ & $\begin{array}{c}\text { Equivalence } \\
\text { ratio } \phi\end{array}$ & $\begin{array}{c}\text { Staging ratio } \\
\alpha[\%]\end{array}$ & $\begin{array}{c}\text { Thermal } \\
\text { power }[\mathrm{kW}]\end{array}$ \\
\hline \hline Point 1 & 55 & 0.75 & 15 & 33 \\
\hline Point 2 & 88 & 0.80 & 50 & 35 \\
\hline
\end{tabular}
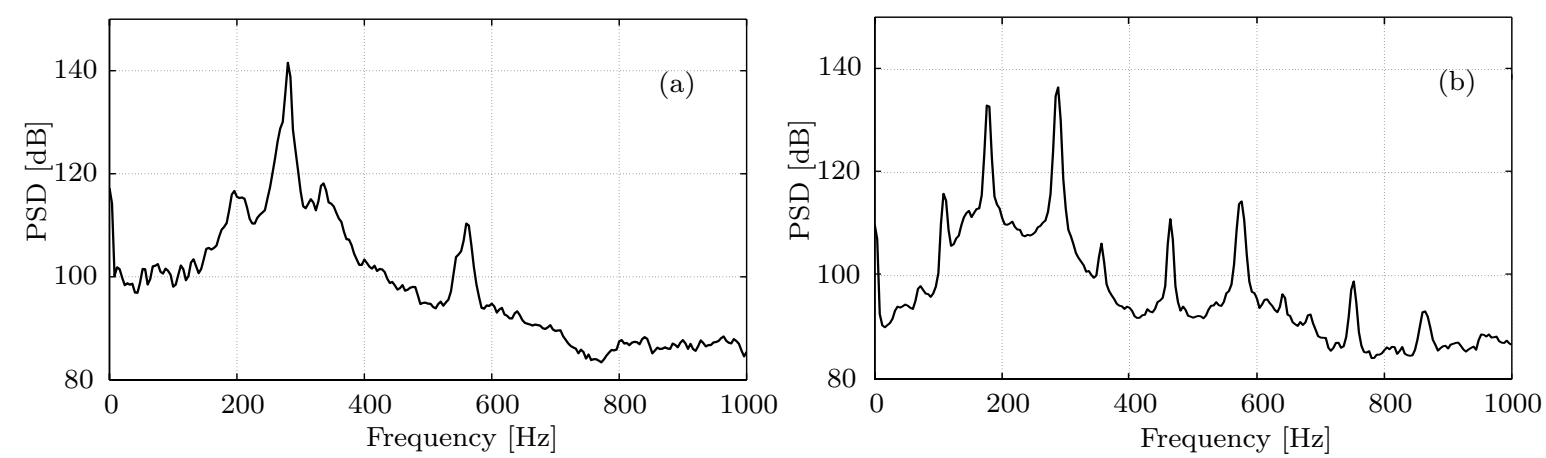

Figure 2. Power Spectral Density of the sound pressure recorded by microphone M1 in the premixing tube. Left: operating point $1\left(L_{c}=0.55 \mathrm{~m}\right)$. Right: operating point $2\left(L_{c}=0.88 \mathrm{~m}\right)$.

A more detailed analysis is now presented in the following section. At the outlet boundary, the chamber exhaust is a square end open to atmospheric conditions. The chamber length was modified in these experiments with an additional element featuring the same cross section. Two different chamber lengths are tested, $L_{c}=0.55 \mathrm{~m}$ and $L_{c}=0.88 \mathrm{~m}$. When the chamber length is changed, the system features a different behavior both in terms of acoustics and aerodynamics for the same flow operating conditions. To obtain two identical flame positions in the chamber, the operating conditions were adjusted to yield the same flame length. They are listed in Tab.1. In the two cases, the burner operates in lean unstable conditions with about the same thermal power.

This gas turbine model combustor was primarily designed to easily characterize the acoustic pressure distribution in the premixer, chamber and feeding lines during self-sustained combustion instabilities. Microphones M1, M2 and M3 are used to determine the premixer acoustic reflection coefficient $R(0)$ at the burner inlet. Reconstruction of the impedance at this location requires a careful calibration in gain and phase of the microphones (B\&K type $49381 / 4$ inch) and the use of a switching technique [5]. The sampling duration was set in all experiments equal to $T=8 \mathrm{~s}$ with a sampling rate of $f_{s}=16384 \mathrm{~Hz}$ allowing enough data collection for spectral analysis in noisy environments. Additional Impedance Measurement Devices (IMD) can be included at different locations on the fuel and air feeding lines to measure their acoustic response [11]. These devices are rectangular and comprise an inner cylinder of the same diameter as the air or fuel supplying pipe in which they are inserted. Three 1/4-inch microphones are flush mounted to get the reflection coefficient at the IMD outlet. These devices were all tested in the impedance tube ITHACA [29] with known termination impedances and the results obtained were in excellent agreement with expected theoretical predictions [9]. 


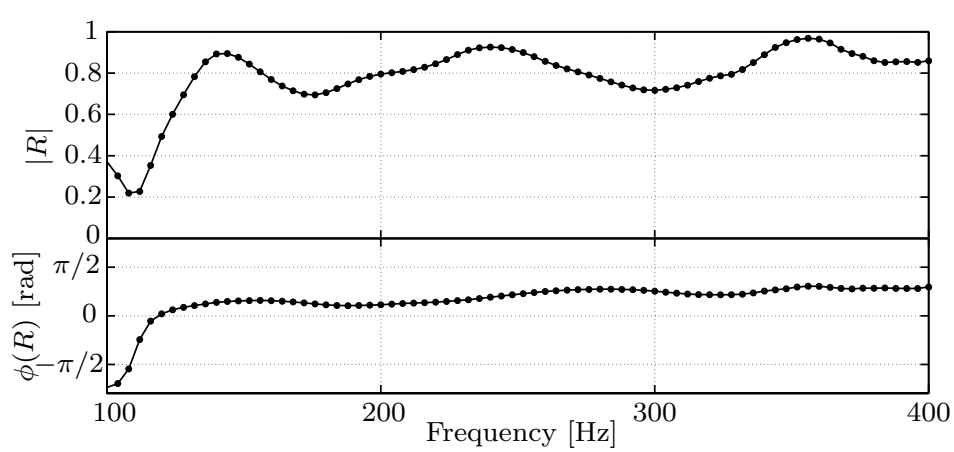

Figure 3. Evolution of the acoustic reflection coefficient $R$ at the premixing tube backplane $(x=0)$ for frequencies from 100 to $400 \mathrm{~Hz}$. The ICS is disabled: the cavity length behind the perforated plate is reduced to zero.

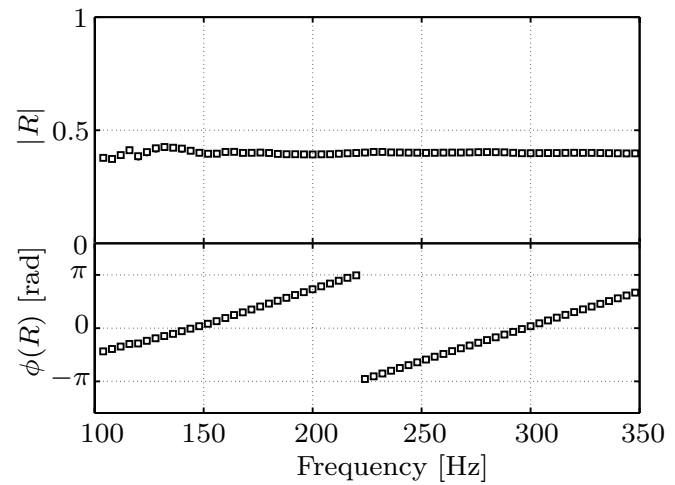

Figure 4. Measurement of the acoustic reflection coefficient in the air feeding lines at $15 \mathrm{~cm}$ from the junction point between the lines and the premixing tube.

\section{Acoustic measurements}

The power spectral density (PSD) of the acoustic pressure recorded by M1 is plotted in figure 2 for the two unstable operating points investigated corresponding to different chamber lengths. The spectrum on the left obtained for the short chamber features one dominant frequency peak at $280 \mathrm{~Hz}$ with a sound level higher than $140 \mathrm{~dB}$. The secondary peaks reach lower levels around $120 \mathrm{~dB}$ (one order of magnitude below the main peak) with frequencies at 196 and $336 \mathrm{~Hz}$. Only the main peak frequency $280 \mathrm{~Hz}$ will be considered in the following. On the right side of figure 2, the power spectral density in the premixer now features two main peaks at 180 and $280 \mathrm{~Hz}$ above $130 \mathrm{~dB}$ for the longer chamber. The secondary peaks lie in this case well below $120 \mathrm{~dB}$ and are not considered. This first observation indicates that the flame seems to amplify different incommensurate frequencies when the geometry of the chamber is changed. More details about the instability mechanisms leading to the two simultaneous unstable frequencies appearing in the long chamber configuration are given in Ref. [10]. In particular, it is shown in this reference that the two frequencies do not appear alternatively but co-exist over the total duration of the experiment.

Microphones located in the premixing tube allow to reconstruct the acoustic reflection coefficient at the rear back plane of the premixer using a three-microphone method [5]. As described in the previous section, the rear backplane of the premixing tube is a perforated plate traversed by a low speed bias flow. The length of the cavity behind this plate can be adjusted to vary the reflection coefficient. When the ICS is disabled, the cavity length is set to zero but the bias flow is conserved through the perforations. Thus the reflection coefficient does not exactly match a perfectly reflecting wall. Black circles in Fig. 3 show the reflection coefficient deduced from the acoustic pressure measurements in the premixing tube when the ICS is disabled as a function of frequency. The phase first increases rapidly at low frequencies $(f>100 \mathrm{~Hz})$ and then features a regular increase up to $1 \mathrm{rad}$, reached at $f=100 \mathrm{~Hz}$. The modulus of the reflection coefficient increases rapidly from 0.2 to 0.9 for low frequencies and then oscillates between 0.7 and 0.9. At the resonant frequencies observed in the experiment (around $280 \mathrm{~Hz}$ for the short chamber, 180 and $280 \mathrm{~Hz}$ for the long chamber), the modulus is close to 0.8 and the phase is $0.75 \mathrm{rad}$. The same types of impedance measurements were carried out in the fuel and air feeding lines with IMD as described in [11]. It is found that the pressure oscillations are still present in the feeding lines up to several meters upstream the premixer. It is only at the flow controller boundaries that these waves are filtered in the present study and the corresponding oscillations disappear in the pressure spectrum. Thus the acoustic 


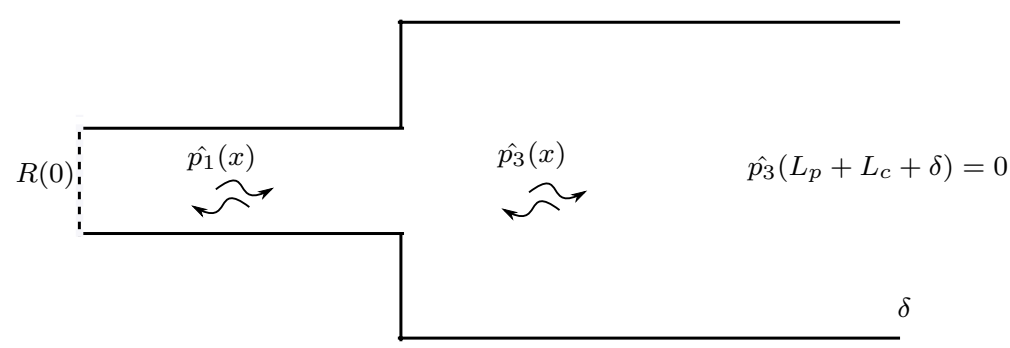

(a) Two-cavity acoustic model

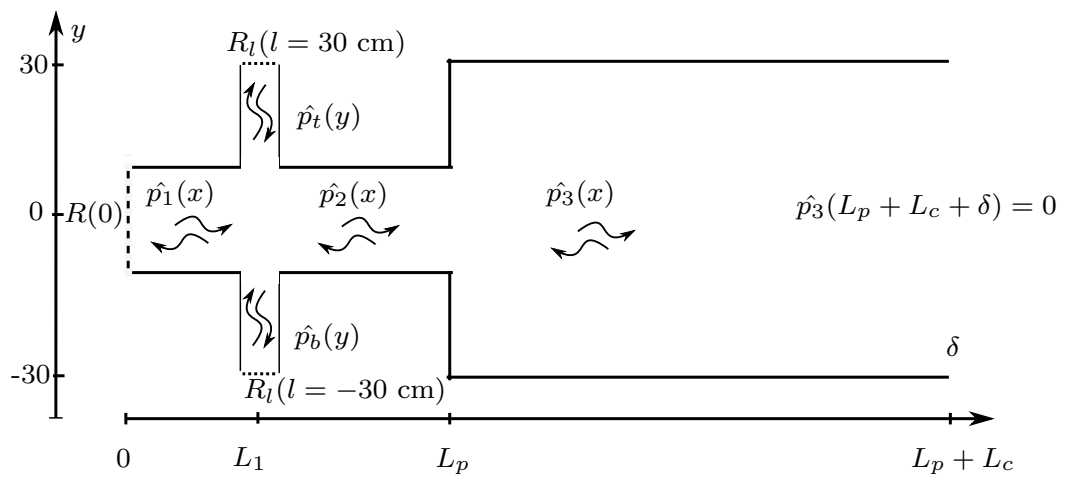

(b) Five-cavity acoustic model

Figure 5. The two acoustic models of the CESAM bench. Inlets are characterized by their acoustic reflection coefficient, the exhaust is open to ambient with the length correction $\delta$.

reflection coefficient at the exit of the flow controller has an influence on the acoustics of the feeding lines. The IMD allows to determine the reflection coefficient in the feeding lines $15 \mathrm{~cm}$ away from the connection point between the supplying pipes and the premixer. Figure 4 presents the evolution of the modulus and phase of this reflection coefficient with respect to frequency. The modulus remains here essentially constant over the frequency range investigated $(|R| \simeq 0.4)$, while the phase features a regular increase with frequency. These measurements were obtained in-situ, meaning that there is no external acoustic forcing. The only acoustic source is due to the flame. In this situation, the acoustic modulation is not constant in amplitude with the frequency so that non-linear effects may slightly interfere and modify these results. Additional measurements of the flow controllers impedance were thus carried out on an acoustically controlled test bench to crosscheck the results [11]. Finally, the impedance at the outlet of the combustion chamber was also measured and does not differ from theoretical predictions if a correction length $\delta=0.85 r_{h}$ is added to the chamber length, where $r_{h}=2.12 \mathrm{~cm}$ indicates the hydraulic radius of the square combustion chamber cross section.

This set of measurements enable to analyze the acoustics of the combustor using a multi-cavity model that takes into account the measured acoustic impedances at the different boundaries. This model and the corresponding predictions are presented in the next section. 


\section{Influence of the premixer inlet reflection coefficient}

The combustor is modeled by a five-cavity model representing the premixing tube, the feeding lines and the combustion chamber as shown in Fig. 5. All variables are decomposed in a mean and harmonic fluctuating components, $a=\bar{a}+a^{\prime}$ with $a^{\prime}=\hat{a} e^{-i \omega t}$, where $\omega=2 \pi f+i \omega_{i}$ denotes the complex angular frequency. The model takes into account neither the mean flow nor the flame transfer function, thus the growing factor given by the imaginary part of the angular frequency can only takes negative or null values in this description. The mean flow in the premixing tube never exceeds $30 \mathrm{~m} \cdot \mathrm{s}^{-1}$ meaning that the Mach number remains below 0.085 . The premixing tube and the feeding pipes are kept at a constant temperature $T_{p}=300 \mathrm{~K}$ while the mean temperature in the combustion chamber is taken equal to $T_{c}=1200 \mathrm{~K}$ in this model. This value corresponds to a mean temperature taking into account various measurements carried out at different locations in the combustion chamber. Acoustic pressures are written as:

$$
\hat{p}_{i}=p_{i}^{+} e^{i k_{i} x}+p_{i}^{-} e^{-i k_{i} x} \quad \text { and } \quad \hat{p}_{j}=p_{j}^{+} e^{i k_{j} y}+p_{j}^{-} e^{-i k_{j} y}
$$

where $i$ equals 1,2 and 3 in the premixing tube before the injection lines $\left(x<L_{1}\right)$, in the premixing tube after the injection lines $\left(L_{1}<x<L_{p}\right)$ and in the combustion chamber $\left(x>L_{p}\right)$ respectively. Subscript $j$ becomes $t$ in the top feeding line and $b$ in the bottom line. The model features ten unknowns which are linked by equations standing for boundary conditions and acoustic conservation laws at the different interfaces. Four equations are obtained by using the reflection coefficient measured at the premixer inlet, combustor outlet, top and bottom air feeding lines. Six equations are obtained by continuity of the acoustic volume flowrate and pressure at the feeding line junctions $\left(x=L_{1}\right)$ and at the end of the premixing tube $\left(x=L_{p}\right)$. Non trivial solutions of the system are obtained when its determinant is zero which allows to determine the eigenfrequencies of the combustor.

The ICS is a key element to control the stability of the combustor. The influence of its acoustic properties is first investigated analytically. In this analysis, the influence of the feeding pipes is not taken into account. The model then degenerates to a system of two coupled cavities representing the premixing tube and the chamber. Acoustic interaction between these two cavities is then controlled by the acoustic coupling index [27]:

$$
\Xi=\frac{S_{p} \rho_{c} c_{c}}{S_{c} \rho_{p} c_{p}} \simeq \frac{S_{p}}{S_{c}} \sqrt{\frac{T_{p}}{T_{c}}}
$$

In the present experimental conditions, $\Xi=0.04$ takes a small value, indicating that acoustic coupling between the two cavities is weak. The combustor eigenmodes can then be linked to the premixer and chamber modes calculated separately, corresponding to the solutions of the two-coupled systems when $\Xi$ is set to zero. The first eigenfrequency of the chamber $f_{c}^{0}$ corresponds to a quarter-wave resonator, the first eigenfrequency of the premixer is a quarter wave resonator with a reflection coefficient $R=|R| e^{i \varphi}$ at the backplane thus:

$$
f_{p}^{0}=\frac{c_{p}}{4 L_{p}}\left(1-\frac{\varphi}{\pi}\right) \quad \text { and } \quad f_{c}^{0}=\frac{c_{c}}{4 L_{c}}
$$

$c_{p}$ and $c_{c}$ indicating the speed of sound in the premixer (length $L_{p}$ ) and the chamber (length $L_{c}$ ) respectively. These frequencies $f_{p}^{0}$ and $f_{c}^{0}$ are plotted in Fig. 6 (dashed lines) as a function of the chamber length varying from $L_{c}=25$ to $90 \mathrm{~cm}$. The first frequency $f_{p}^{0}$ is independent on the chamber length remains constant and equal here to $281 \mathrm{~Hz}$. The eigenfrequency of the chamber cavity $f_{c}^{0}$ naturally decreases with the chamber length. The two curves crosses each other when the chamber length is equal to $L_{c}=0.62 \mathrm{~cm}$, a value which is close to the short chamber length $L_{p}=55 \mathrm{~cm}$ tested here.

The two-cavity model can also be used to compute the first two eigenfrequencies $f_{p c}^{0}$ and $f_{p c}^{1}$ of the system by taking into account the finite value of the coupling index $\Xi=0.04$ for different chamber lengths and reflection coefficients at the premixer backplane. This backplane is first considered as a wall when 
Table 2

Evolution of the first eigenfrequencies $f_{p c}^{0}$ and $f_{p c}^{1}$ (in $\mathrm{Hz}$ ) of the combustor for different premixer inlet reflection coefficients $R(0)$ and chamber length $L_{c}$ obtained with the two-cavity model and compared with experimental results. The evolution of the first eigenfrequencies of the premixer $\left(f_{p}^{0}\right)$ and chamber $\left(f_{c}^{0}\right)$ cavities calculated separately is also indicated.

\begin{tabular}{|l|ccccc|}
\hline & $L_{c}$ & $f_{c}^{0}$ & $f_{p}^{0}$ & $f_{p c}^{0}$ & $f_{p c}^{1}$ \\
\hline$R(0)=1$ & 0.55 & 322 & 369 & 300 & 395 \\
$R(0)=0.8$ & 0.55 & 322 & 369 & 300 & 395 \\
$R(0)=0.8 \mathrm{e}^{i 0.75}$ & 0.55 & 322 & 281 & $\mathbf{2 5 8}$ & 349 \\
Experiment & 0.55 & $\times$ & $\times$ & 280 & $\times$ \\
\hline$R(0)=1$ & 0.88 & 191 & 369 & 186 & 370 \\
$R(0)=0.8$ & 0.88 & 191 & 369 & 186 & 370 \\
$R(0)=0.8 \mathrm{e}^{i 0.75}$ & 0.88 & 191 & 281 & $\mathbf{1 8 3}$ & $\mathbf{2 9 0}$ \\
Experiment & 0.88 & $\times$ & $\times$ & 180 & 284 \\
\hline
\end{tabular}

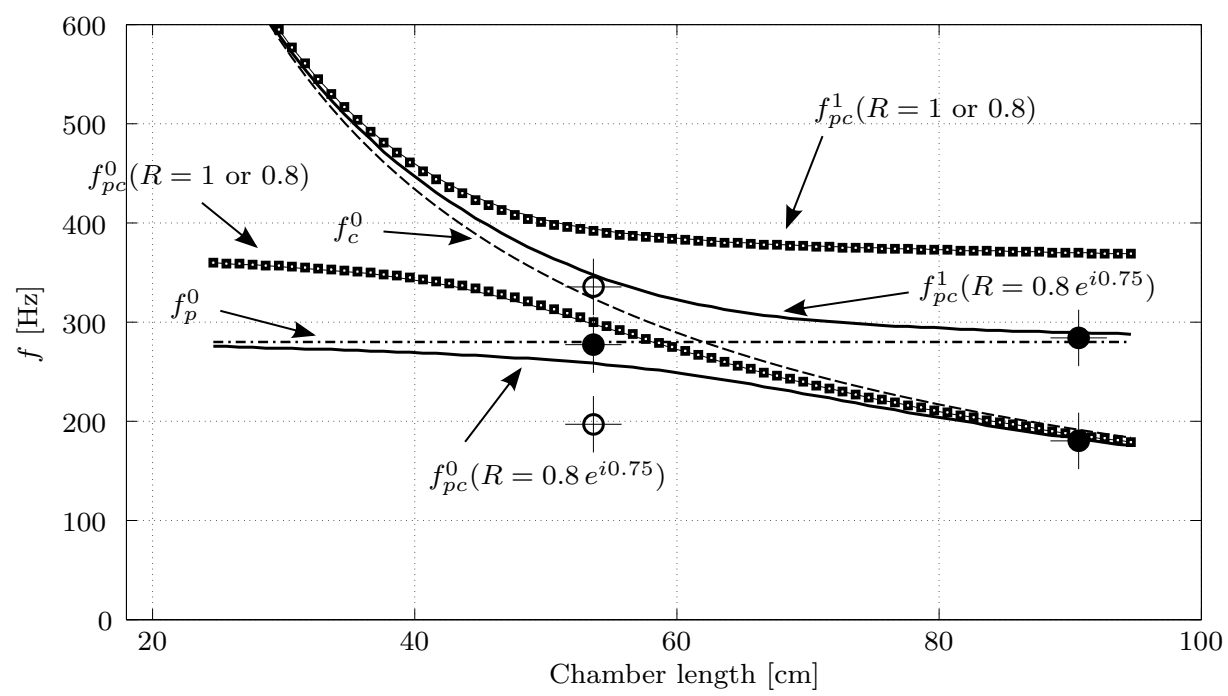

Figure 6. Eigenfrequencies of the combustor obtained with the two-cavity model as a function of the chamber length $L_{c}$ for different acoustic reflection coefficients at the premixer backplane: $R=1, R=0.8$ and $R=0.8 e^{i 0.75}$. The first eigenfrequencies of the premixer $f_{p}^{0}$ and chamber $f_{c}^{0}$ calculated separately are also plotted (dashed lines). Experimental data gathered for $L_{c}=55$ and $88 \mathrm{~cm}$ are indicated with crossed-circles: filled circles feature the loudest peak frequency in the spectrum while the empty circles stand for secondary peaks.

$R=1$; calculations are then reconducted with the values measured for the modulus and phase of the premixer reflection coefficient $R=0.8 e^{i 0.75}$ taken near the premixer eigenfrequency $f_{p}^{0}=280 \mathrm{~Hz}$. The evolution of the two frequencies $f_{p c}^{0}$ and $f_{p c}^{1}$ are plotted in Fig. 6 as functions of the combustion chamber length for different estimates of the premixer inlet reflection coefficient. These analytical predictions are also compared to the frequency peaks measured in the sound pressure spectra for the two chamber lengths $L_{c}=55 \mathrm{~cm}$ and $L_{c}=88 \mathrm{~cm}$. Values for the different eigenfrequencies obtained for these two geometrical configurations are listed in Tab. 2.

The eigenfrequencies computed for $R=1$ or $R=0.8$ show a similar evolution in Fig. 6 . Modifying the value of the modulus of the premixer inlet reflection coefficient has no effect on the evolution of these frequencies when the chamber length is modified. The first frequency $f_{p c}^{0}$ lies relatively close to one of the measured peak frequencies for the two combustor lengths explored. In this situation, the second eigenfrequency $f_{p c}^{1}$ lies however always far away from any measured peak frequency and is overestimated for the two chamber lengths. The difference reaches about $100 \mathrm{~Hz}$ for the long chamber. 

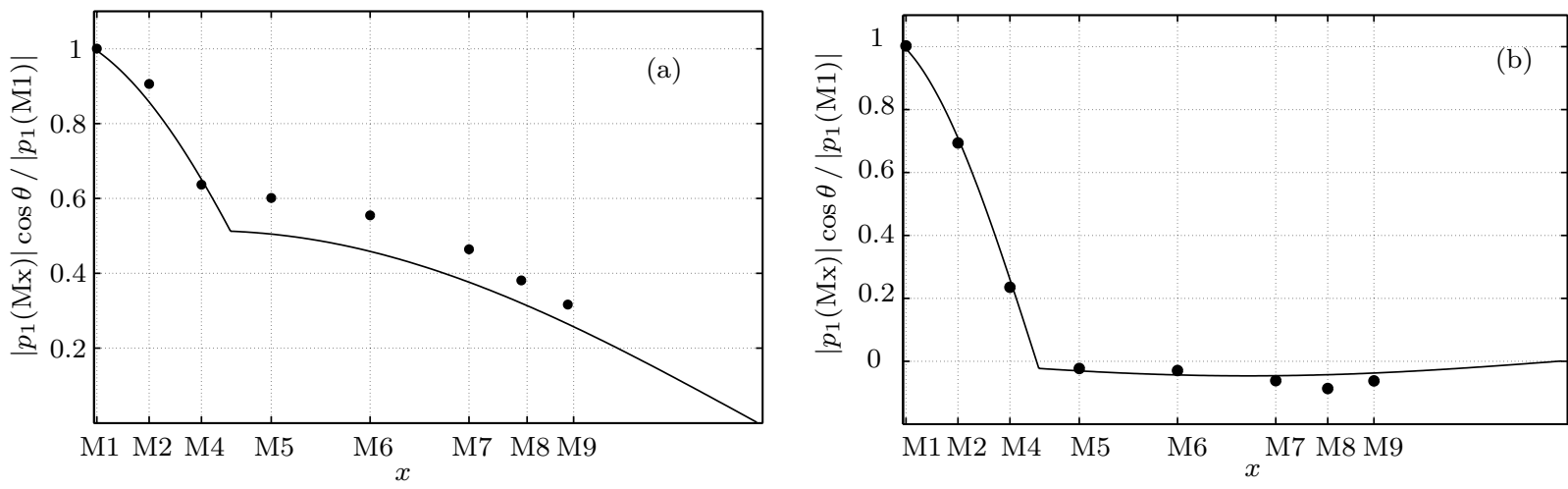

Figure 7. Pressure distributions measured (dots) and predicted (lines) along the premixing tube and the long chamber (Point 2, $L=0.88 \mathrm{~m}$ ): (a) $f_{p c}^{0}(\exp )=180 \mathrm{~Hz}$ and $f_{p c}^{0}($ theo $)=183 \mathrm{~Hz}$, (b) $f_{p c}^{1}(\exp )=284 \mathrm{~Hz}$ and $f_{p c}^{1}($ theo $)=290 \mathrm{~Hz} . \theta$ is the phase between the microphones, allowing to plot the envelope of the signal.

By taking into account the measured phase of the premixer inlet reflection coefficient $R=0.8 e^{i 0.75}$ in the two-cavity model, the eigenfrequencies $f_{p c}^{0}$ and $f_{p c}^{1}$ are displaced. As shown by the continuous lines in Fig. 6, the phase of the reflection coefficient has a strong effect on the eigenfrequencies evolution. The first mode $f_{p c}^{0}$ tends towards the premixer eigenfrequency $f_{p}^{0}$ when the chamber length is reduced to small values. The same limit $f_{p}^{0}$ is reached by the second eigenfrequency $f_{p c}^{1}$ for large chamber lengths. When the acoustic coupling index $\Xi$ takes small but finite values, the premixer eigenfrequency $f_{p}^{0}$ calculated as if the cavities were decoupled corresponds to the first eigenfrequency $f_{p c}^{0}$ of the system for short chambers and to the second mode $f_{p c}^{1}$ for large chambers.

For the long chamber $L_{c}=0.88 \mathrm{~m}$, the first frequency $f_{p c}^{0}=183 \mathrm{~Hz}$ is relatively well estimated by the chamber eigenfrequency $f_{c}^{0}=191 \mathrm{~Hz}$ while Table 2 shows that the second mode $f_{p c}^{1}=290 \mathrm{~Hz}$ is close to the premixer frequency $f_{p}^{0}=281 \mathrm{~Hz}$ as if the two cavities were indeed perfectly decoupled. Table 2 also shows that the two-cavity model remarkably predicts the frequency peaks observed experimentally: $f_{p c}^{0}=183 \mathrm{~Hz}$ (theoretical) to be compared to $180 \mathrm{~Hz}$ and $f_{p c}^{1}=290 \mathrm{~Hz}$ to be compared to $284 \mathrm{~Hz}$ observed experimentall.

A deeper analysis consists in comparing the predicted and measured pressure distributions along the combustor at those frequencies. Results are plotted in Fig. 8(a) and (b) for $f_{p c}^{0}$ and $f_{p c}^{1}$ respectively. These data are compared to the pressure recorded at the different microphone locations (M1 to M9). Predictions (continuous lines) lie close to the experimental values. The first mode (a) is called a "chamber mode" because its oscillation frequency is determined solely by the chamber length. Unexpectedly, its maximum amplitude is however reached in the premixer. The pressure oscillation in the chamber is in phase with the pressure oscillation in the premixer and its amplitude at the flame location (M5) is about half that reached at the premixer backplane. The second mode is called a "premixer mode" because its frequency is only associated to the premixer length (and inlet impedance). The oscillation in the chamber is in this mode in phase opposition and significantly weaker than in the premixer. For the long chamber, the model allows to predict the experimental data both for the frequencies and pressure distributions if the premixer reflection coefficient is correctly determined. In this case, the premixer and chamber behave as uncoupled cavities because the acoustic coupling index $\Xi=0.04$ is small and the eigenfrequencies of the two cavities are significantly different.

The situation for the short chamber $L_{c}=0.55 \mathrm{~m}$ is much more complex even though the coupling index still features the same small value $\Xi=0.04$. This operating condition is close to the one when the eigenfrequency of the chamber mode $f_{c}^{0}$ exactly matches the eigenfrequency of the premixing tube $f_{p}^{0}$. This condition is reached for $L_{c}=0.62 \mathrm{~m}$ where veering takes place. This veering phenomenon, well 
documented in Refs. [17,22,26], appears when the eigenfrequencies of two sub-systems match each other. In this case, the eigenmodes of the global system are shifted with respect to the frequencies calculated for perfectly decoupled cavities as shown in Fig. 6 even though the acoustic coupling index is small. This phenomenon also appears in the present situation for $L_{c}=0.55 \mathrm{~m}$ when the eigenmodes of the two cavities are close. The two-cavity model yields in this case roots featuring a frequency shift with respect to the uncoupled situation as visible in Table 2. The measured spectrum features also a complex behavior for this chamber length $L_{c}=0.55 \mathrm{~m}$, where a main frequency peak at $280 \mathrm{~Hz}$ was identified together with two low level secondary peaks at 200 and $336 \mathrm{~Hz}$ (Fig. 2). The main peak identified at $280 \mathrm{~Hz}$ (black dot) is located between the two first computed frequencies (continuous lines) but close to $f_{p}^{0}=281 \mathrm{~Hz}$. The second peak frequency at $336 \mathrm{~Hz}$ lies close to the second mode $f_{p c}^{1} \simeq f_{c}^{0}=322 \mathrm{~Hz}$, but it is difficult to associate these peak frequencies to one of the eigenmodes of the combustor. The pressure distribution along the combustor is used to clarify the situation for the main peak frequency observed at $280 \mathrm{~Hz}$. Figure 8 shows the pressure distribution as function of the combustor location predicted by the model for a frequency $f_{p c}^{1}$ (theo) $=349 \mathrm{~Hz}$ (continuous line) which is compared to measured data collected at $f_{p c}^{0}(\exp )=280 \mathrm{~Hz}$ (dots). Surprisingly, the two evolutions match quite well. This pressure distribution with fluctuations in the premixer in phase opposition with those in the chamber clearly indicates that the structure of this mode is determined by the premixer cavity $f_{p}^{0}=280 \mathrm{~Hz}$.

The two-cavity model yields accurate predictions of the eigenmodes of the system when they are clearly separated (long chamber). In this situation, the system behaves like two uncoupled cavities because the acoustic coupling index $\Xi$ is small and the frequencies of the so called independent cavities are sufficiently different. The modes of the system can then easily be determined by examining the modes of each cavity separately. When the modes of these two cavities merge by decreasing the chamber length, veering takes place manifested by a frequency shift of the calculated frequencies with respect to the modes of the cavities calculated separately. It is then not possible to consider uncoupled cavities even for very small values of the acoustic coupling index between the premixer and the chamber (small chamber). It was also shown that in this case experiments yield a complex pressure distribution where it is difficult to match the observed frequencies with the different eigenmodes predicted. Examination of the pressure distribution along the combustor is then a way to elucidate the structure of the different modes observed. In the case explored in this study, it was possible to show that the main peak frequency associated to the short chamber $L_{c}=0.55 \mathrm{~m}$ still corresponds to a premixer mode. In principle this mode is sensitive to slight modifications of the acoustic filed in the premixer. To tackle the problem, the five-cavity model is used in the next section to analyze the influence of the injection lines.

\section{Influence of the feeding lines}

One possibility to improve predictions of the eigenfrequencies is to take into account the influence of the injection lines. The two-cavity model analyzed in the previous section showed that there is always a main peak emerging in the measured pressure spectrum associated to the premixer for the long and short combustion chambers. It is then worth examining the influence of the feeding lines acoustics on the pressure distribution. The acoustic impedance in the air feeding pipes was measured $30 \mathrm{~cm}$ away from the premixer as shown in Fig. 5. The modulus is roughly constant and equal to 0.4 , and the phase features a linear growth $\varphi(f)$ with respect to the frequency (Fig. 4). This reflection coefficient can then modeled as $R(y=0.30)=0.4 e^{i \varphi(f)}$, where $\varphi(f)=\pi \omega / 300-\pi / 2$.

Air feeding lines are modeled in the five-cavity model with two 30-cm long and 3-cm diameter tubes connected to the premixer axis. The eigenfrequencies of this new acoustic model are determined as a function of the chamber length. Results are plotted in Fig. 9. The computed eigenfrequencies $f_{p c}^{0}$ and $f_{p c}^{1}$ 


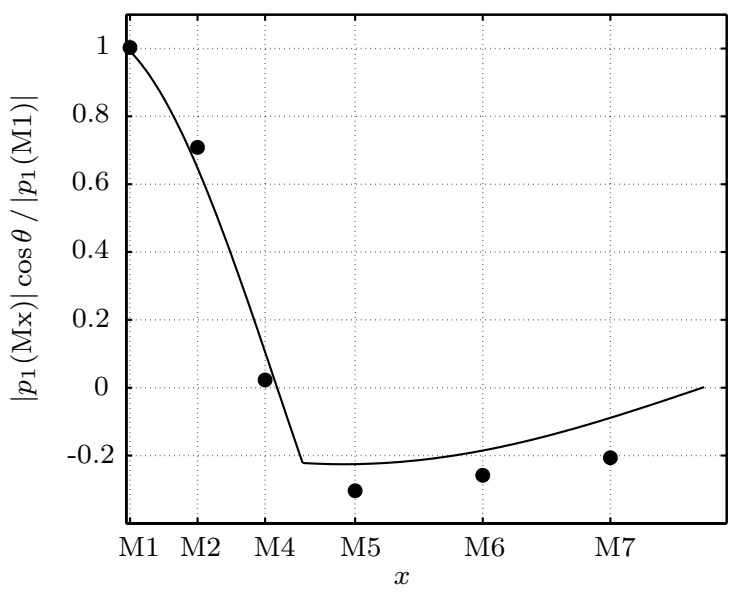

Figure 8. Pressure distribution measured at $f_{p c}^{0}(\exp )=280 \mathrm{~Hz}$ (dots) and predicted at $f_{p c}^{1}$ (theo) $=349 \mathrm{~Hz}$ (lines) along the premixing tube and the short chamber with the two-cavity model (Point 1, $L=0.55 \mathrm{~m}$ ). $\theta$ is the phase between the microphones, allowing to plot the envelope of the signal.

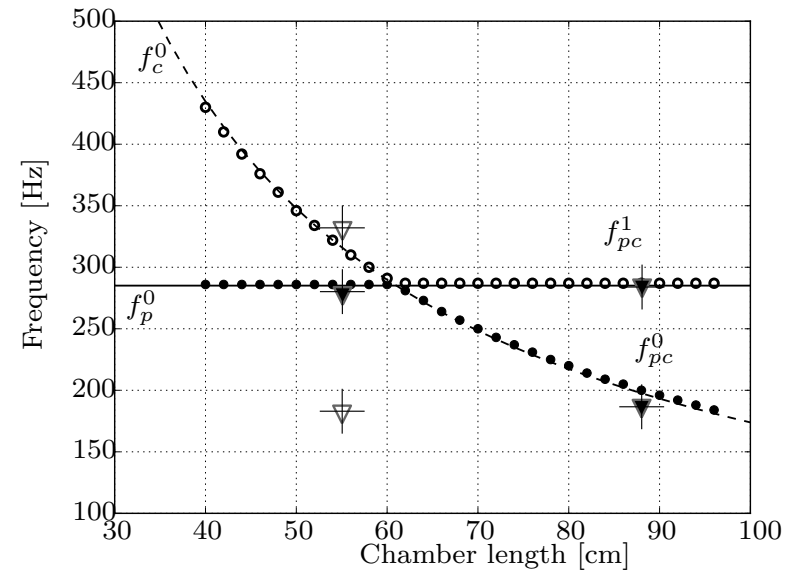

Figure 9. Eigenfrequencies of the system predicted by the fivecavity model (circles) as a function of the chamber length. The two modes $f_{p c}^{0}$ and $f_{p c}^{1}$ are close to the modes of each cavity (premixer: continuous line, chamber: dashed line). Filled triangles represent the resonant frequencies determined experimentally, the empty triangles feature the secondary peaks observed with the short chamber.

are represented with black and white circles respectively. These predicted eigenfrequencies are compared to the experimental data (triangles) and to the modes of the premixer (continuous line) and the chamber (dashed line) calculated for a premixer perfectly decoupled from the combustion chamber.

It is striking that the frequency shift observed between the eigenmodes of the combustor $f_{p c}^{0}$ and $f_{p c}^{1}$ and predictions for the premixer $f_{p}^{0}$ and combustion chamber $f_{c}^{0}$ modes presented in Figure 6 is now reduced to zero when the acoustics of the feeding lines is taken into account. Modes in this case are well decoupled for the long $\left(L_{c}=0.88 \mathrm{~m}\right)$ as for the short $\left(L_{c}=0.55 \mathrm{~m}\right)$ combustion chamber. This model first confirms modes predictions for the long chamber where the two main peaks identified in the measurements correspond to $f_{p c}^{0} \simeq f_{c}^{0}$ associated to a chamber mode and $f_{p c}^{1} \simeq f_{p}^{0}$ associated to a premixer mode. Moreover, it also retrieves a correct frequency of the main peak emerging in the measurements collected for the short combustion chamber. It confirms that in this case this frequency $f_{p c}^{0} \simeq f_{p}^{0}=280 \mathrm{~Hz}$ is associated to a premixer mode which measured structure and frequency now match with predictions. It is also possible to identify with this improved model that the secondary peak observed at $336 \mathrm{~Hz}$ matches $f_{p c}^{1} \simeq f_{c}^{0}=322 \mathrm{~Hz}$ the mode associated to the combustion chamber. The secondary peak frequency at $180 \mathrm{~Hz}$ is not predicted by this model and this point is still under current investigation. One difficulty is that the peak frequencies observed in the spectrum at 180 and $336 \mathrm{~Hz}$ are very weak compared to the main frequency $280 \mathrm{~Hz}$. Post-processing of experimental data barely allows to extract their pressure distribution.

It is interesting to examine the reason why veering with the two-cavity model does not manifest the same way with the five-cavity model. This can be done by examining the imaginary component of the roots of the dispersion relation. The imaginary contribution provides the damping of the mode. A negative value indicates a stable damped mode while a positive value stands for an unstable amplified mode. In the present model, no acoustic source is included and the modes are all damped or marginally stable. Table 3 
Table 3

Complex eigenfrequencies computed with the two models for two different chamber lengths.

\begin{tabular}{lccc}
\hline & $L_{c}$ & $f_{p c}^{0}$ & $f_{p c}^{1}$ \\
\hline Two-cavity model & 0.55 & $258-i 2.5$ & $349-i 13$ \\
Two-cavity mode & 0.88 & $183-i 2.4$ & $290-i 23$ \\
\hline Five-cavity model & 0.55 & $283-i 151$ & $318-i 0.77$ \\
Five-cavity model & 0.88 & $201-i 0.71$ & $283-i 152$ \\
\hline
\end{tabular}

presents the complex eigenfrequencies computed with the two models investigated. The two-cavity model indicates that damping is always of the same order of magnitude for the two modes $f_{p c}^{0}$ and $f_{p c}^{1}$ and for all chamber lengths explored. With this model, the two modes are identically damped. The five-cavity model shows that for each chamber length the two modes feature very different imaginary components. In this case, one mode is always more damped than the other. This interesting feature seems to show that, in weakly coupled cavities systems, matching the mode frequencies of the different cavities does not necessarily lead to substantial differences with the modes determined for well decoupled cavities as long as the damping of each mode is sufficiently different.

This novel and original conclusion is under further investigation since more rigorous proofs are still needed. Indeed, the damping of the mode associated with the frequency $f_{p c}^{0}$ is strongly negative $\left(-151 \mathrm{~s}^{-1}\right)$. With this damping, the mode could not be observable experimentally. There is definitively a lack of precision on this value which may come from the modeling. Feeding lines have been modeled by two transverse cavities with an equivalent area of the cross section and connected at the distance $L_{1}$ from the back plane. Namely, the similitude is not exact and modifications on either the cavity cross section or the cavity position yield substantial variations of the damping coefficient. Moreover, this large damping questions the validity limit of the measured reflexion coefficients of the feeding lines. Measurements have been carried out in situ with a constant amplitude modulation. The acoustic impedances may be strongly modified when the modulation signal is damped. Even if the accuracy of the values is improvable by improving the model, this work mainly shows that modeling efforts are required in order to take into account veering and complex acoustic couplings. Finally, it shows that the damping influences the coupling between cavities. This could be adjusted on combustors by changing wall material, cavity geometry or by designing feeding lines which could be used as dampers. In any case, damping is a parameter very complicated to measure experimentally and a better knowledge of this parameter on practical devices should significantly help in understanding and modeling acoustics in combustors.

\section{Conclusion}

An experimental investigation was conducted on a gas turbine model combustor open to atmospheric conditions featuring a premixing tube connected to a combustion chamber which length can be modified. This system features a weak acoustic coupling index $\Xi$ as in many laboratory and practical combustors. It was shown that it is then possible to easily reproduce the acoustic field in the setup when the first eigenmodes of the combustor are well separated. This was the case for the long combustion chamber explored in this study where the first mode is only controlled by the chamber acoustics while the second one is only controlled by the premixer acoustics. Reducing the acoustic coupling index at the design stage of a combustor enables then to easily tune the pressure distribution by independent modifications of the combustion chamber or the premixer elements, except when these frequencies match. This situation was explored here for the short combustion chamber where the premixer and combustion chamber eigenfrequencies were made close to each other. It was shown in this case that it is necessary to analyze the damping of each mode to determine whether they can be considered as decoupled or not. Tuning the 
damping of the different modes may then be envisaged as a solution to decouple acoustic modes. The whole analysis was conducted without integrating any flame model. This should be done in a near future to see if conclusions are still valid.

\section{References}

[1] V. Bellucci, P. Flohr, and C. O. Paschereit. Numerical and experimental study of acoustic damping generated by perforated screens. AIAA J., 42(8):1543-1549, 2004.

[2] S. Camporeale, B. Fortunato, and G. Campa. A finite element method for three-dimensional analysis of thermo-acoustic combustion instability. Journal of Engineering for Gas Turbines and Power, 133:011506 (13 pages), 2011.

[3] S. Candel. Combustion dynamics and control: Progress and challenges. Proceedings of the Combustion Institute, 29(1):1 $-28,2002$.

[4] S. Candel, D. Durox, S. Ducruix, A.-L. Birbaud, N. Noiray, and T. Schuller. Flame dynamics and combustion noise: progress and challenges. International Journal of Aeroacoustics, 8(1):1-56, 2009.

[5] J. Y. Chung. Cross-spectral method of measuring acoustic intensity without error caused by instrument mismatch. Journal of the Acoustical Society of America, 64(6):1613-1616, 1978.

[6] A. Dowling. The calculation of thermoacoustic oscillations. Journal of Sound and Vibration, 180(4):557-581, 1995.

[7] A. P. Dowling and S. R. Stow. Acoustic analysis of gas turbine combustors. Journal of Propulsion and Power, 19(5):751-764, Sep-Oct 2003.

[8] E. Gullaud and F. Nicoud. Effect of perforated plates on the acoustics of annular combustors. AIAA Journal, in press, 2012 .

[9] A. Lamraoui. Acoustique et dynamique de flamme dans un foyer turbulent prémélangé swirlé : application à l'étude du bruit de combustion dans les chambres de turbines à gaz. PhD thesis, Ecole Centrale Paris, 2011.

[10] A. Lamraoui, F. Richecoeur, S. Ducruix, and T. Schuller. Experimental analysis of simultaneous non-harmonically related unstable modes in a swirled combustor. In Proceedings of ASME Turbo Expo, number GT2011-46701, 2011.

[11] A. Lamraoui, F. Richecoeur, T. Schuller, and S. Ducruix. A methodology for on the fly acoustic characterization of the feeding lines impedances in a turbulent swirled burner. Journal of Engineering of Gas Turbine and Power, 133(1):011504 (7 pages), 2011.

[12] A. Laverdant, T. Poinsot, and S. Candel. Influence of the mean temperature field on the acoustic mode structure in a dump combustor. Journal of Propulsion and Power, 2(4):311-316, 1985.

[13] K. R. McManus, T. Poinsot, and S. Candel. A review of active control of combustion instabilities. Prog. Energy Combust. Sci., 19:1-29, 1993.

[14] F. Nicoud, L. Benoit, C. Sensiau, and T. Poinsot. Acoustic modes in combustors with complex impedances and multidimensionnal active flames. AIAA Journal, 45(2):426-441, 2007.

[15] F. Nicoud and K. Wieczorek. About de zero mach number assumption in the calculation of thermoacoustic instabilities. International journal of spray and combustion dynamics, 1(1):67-112, 2009.

[16] M. Oschwald, Z. Farago, G. Searby, and F. Cheuret. Resonance frequencies and damping of a combustor acoustically coupled to an absorber. Journal of Propulsion and Power, 24(3):524-533, 2008.

[17] C. Pierre. Mode localization and eigenvalue loci veering phenomena in disordered structures. Journal of Sound and Vibration, 126(3):485 - 502, 1988.

[18] T. Poinsot, A. Trouve, D. Veynante, S. Candel, and E. Esposito. Vortex-driven acoustically coupled combustion instabilities. Journal of Fluid Mechanics, 177:265-292, 1987.

[19] T. Poinsot and D. Veynante. Theoretical and Numerical Combustion (2nd Edition). Edwards, 2005.

[20] G. A. Richards, D. L. Straub, and E. H. Robey. Passive control of combustion dynamics in stationary gas turbines. J. Prop. Power, 19(5):795-810, 2003. 
[21] S. Roux, G. Lartigue, T. Poinsot, and T. Bérat. Studies of mean and unsteady flow in a swirled combustor using experiments, acoustic analysis and large eddy simulations. Combustion and Flame, 141(1-2):40-54, 2005.

[22] A. Saito, M. Castanier, and C. Pierre. Estimation and veering analysis of nonlinear resonant frequencies of cracked plates. Journal of Sound and Vibration, 326(3-5):725 - 739, 2009.

[23] G. Searby, A. Nicole, M. Habiballah, and E. Laroche. Prediction of the efficiency of acoustic damping cavities. Journal of Propulsion and Power, 24(3):516-523, 2008.

[24] L. Selle, L. Benoit, T. Poinsot, F. Nicoud, and W. Krebs. Joint use of compressible large-eddy simulation and helmholtz solvers for the analysis of rotating modes in an industrial swirled burner. Combustion and Flame, 145:194-205, 2006.

[25] J. Sisco, Y. Yu, R. Sankaran, and W. Anderson. Examination of mode shapes in an unstable model combustor. Journal of Sound and Vibration, 330:61-74, 2011.

[26] N. G. Stephen. On veering of eigenvalue loci. Journal of Vibration and Acoustics, 131(5):054501, 2009.

[27] N. Tran. Towards Predictive Numerical Simulations of Advanced Combustors Experiments and Modelling of Instabilities in Acoustically Controlled Combustion Chambers. PhD thesis, Ecole Centrale Paris, 2008.

[28] N. Tran, S. Ducruix, and T. Schuller. Damping combustion instabilities with perforates at the premixer inlet of a swirled burner. Proceedings of the Combustion Institute, 32:2917-2924, 2009.

[29] N. Tran, S. Ducruix, and T. Schuller. Passive control of the inlet acoustic boundary condition of a swirled burner at high amplitude combustion instabilities. Journal of Engineering for Gas Turbines and Power, 131(5):051502 (7 pages), 2009.

[30] G. Walz, W. Krebs, S. Hoffmann, and H. Judith. Detailed analysis of the acoustic mode shapes of an annular combustor. Journal of Engineering for Gas Turbines and Power, 124(1):3-9, 2002.

[31] K. Yu, A. Trouvé, and J. Daily. Low-frequency pressure oscillations in a model ramjet combustor. Journal of Fluid Mechanics, 232:47-72, 1991. 